\author{
ARTIGO \\ dO https://doi.org/10.22481/praxisedu.v16i37.4995
}

\title{
ESCOLA DE TEMPO INTEGRAL E FORMAÇÃO DOCENTE: O QUE PENSAM OS SUJEITOS SOBRE ESSA EXPERIÊNCIA
}

\author{
FULL-TIME SCHOOL AND TEACHING TRAINING: WHAT THE SUBJECTS THINK \\ ABOUT THIS EXPERIENCE
}
ESCUELA DE TIEMPO INTEGRAL Y FORMACIÓN DOCENTE: QUÉPIENSAN LOS SUJETOS SOBRE DICHA EXPERIENCIA

Erika Christianne Sousa Pereira de Almeida

Rede Municipal de Educação de São Luís - Brasil

Lélia Cristina Silveira de Moraes

Universidade Federal do Maranhão - Brasil

\begin{abstract}
Resumo: O presente texto discute a escola de tempo integral, destacando aspectos como a formação continuada de professores, as condições de trabalho docente e o currículo. Resultante de pesquisa, cuja abordagem é de cunho qualitativo, contou com a participação de 11 sujeitos que expressaram suas percepções sobre alguns aspectos, considerados por eles fundamentais para consolidação da escola de tempo integral. Os dados foram coletados por meio de observações, com inserções na escola e registro em diário de campo, entrevistas semiestruturadas. Fundamentamos a pesquisa em: Cavaliere (2009), Moraes (2009), Tardif e Lessard (2014), Bogdan e Biklen (1994), dentre outros. Como resultado constatou-se a necessidade de formação continuada de professores específica para a realidade da escola de tempo integral, para que possam discutir sobre os desafios, possibilidades e ações. Concluímos que a escola de tempo integral é terreno fértil para as discussões sobre a educação. No que se refere a essa realidade específica, está em andamento uma experiência rica, que transcende o campo técnicoinstrumental, as percepções dos sujeitos expressam com muita propriedade alguns aspectos que repercutem e compõem essa experiência formativa.
\end{abstract}

Palavras-chave: Escola; Formação docente; Tempo integral

\begin{abstract}
This article discusses the full-time school, highlighting aspects such as the continuing teacher training, teaching work conditions and the curriculum. Resulting from research, which approach is qualitative, it was attended by 11 subjects who expressed their perceptions about some aspects, considered by them, fundamental for consolidating the school full time. Data were collected through observations, semi-structured interviews, school insertions and field diary recordings. We base the research in Cavaliere (2009), Moraes (2009), Tardif and Lessard (2014), Bogdan and Biklen (1994), among others. As a result, it was noted the need for continuous teacher training specifically to the reality of the full-time school, so they can discuss about the challenges, possibilities and actions. We conclude that the full-time school is fertile ground for discussions about education, as far as this specific reality is concerned, a rich experience is underway that transcends the technical-instrumental field, the subjects' perceptions very well express some aspects which reflect and compose this formative experience.
\end{abstract}


Keywords: School; Teacher training; Full-time

Resumen: El presente texto discute la escuela de tiempo integral, señalando aspectos como la formación continuada de profesores, las condiciones de trabajo docente y el currículo. Resultado de una investigación, cuyo abordaje es de enfoque cualitativo, tuvo la participación de 11 sujetos que expresaron sus percepciones sobre algunos aspectos, considerados por ellos fundamentales para la consolidación de la escuela de tiempo integral. Los datos fueron recogidos a través de observaciones, con inserciones en la escuela y registro en diario de campo, entrevistas semiestructuradas. Fundamentamos la investigación con los aportes de Cavaliere (2009), Moraes (2009), Tardif y Lessard (2014), Bodgan y Biklen (1994) y otros. Los resultados evidencian la necesidad de formación continuada de profesores específica para la realidad de la escuela de tiempo integral, para que pueda discutir sobre desafíos, posibilidades y acciones. Concluimos que la escuela de tiempo integral es terreno fértil para las discusiones sobre la educación. En lo que se refiere a esa realidad específica, está en marcha una experiencia rica, que transciende al campo técnico-instrumental, las percepciones de los sujetos expresan con mucha propiedad algunos aspectos que repercuten y componen esa experiencia formativa.

Palabras clave: Escuela; Formación docente; Tiempo integral

\section{Introdução}

Dentre os temas recorrentes na educação brasileira, a educação integral e educação em tempo integral têm destaque, desde a primeira metade do século $\mathrm{XX}$, mais especificamente na década de 1950, com Anísio Teixeira, nas chamadas "escolas-classe" e "escolas-parque" na Bahia, passando pela polêmica experiência idealizada por Darcy Ribeiro dos Centros Integrados de Educação Pública (CIEP’s) no Rio de Janeiro, nos anos 1980/90 (BRASIL, 2009). No governo de Fernando Collor (1990/92), foram construídas novas unidades com a nomenclatura de Centros Integrados de Atendimento à Criança (CIAC's) e posteriormente, no governo de Itamar Franco, os Centros de Educação Integral à Criança e ao Adolescente (CAIC's) 1992/94, até nos anos 2000, quando ganha novamente destaque em projetos do setor público seja em ações municipais, estaduais e federais.

O presente texto foi elaborado a partir de uma pesquisa desenvolvida no Estado do Maranhão. No contexto deste estudo, fazemos um recorte na pesquisa e temos como objetivo discutir a escola de tempo integral, com foco na formação continuada de professores, nas condições de trabalho docente e no currículo, a partir das percepções de professores que atuam na escola de tempo integral.

A pesquisa foi realizada em uma escola da Rede Municipal, localizada em um dos municípios que compõem a ilha de São Luís, a qual vivencia a experiência de tempo integral, desde 2008, contando com a participação de 11 sujeitos: professores, coordenadora pedagógica 
e secretária adjunta de gestão pedagógica. Esse município tem tido destaque em âmbito nacional, nas avaliações do IDEB $^{1}$, com a escola de tempo integral. De acordo com o Plano Municipal de Educação (SÃO JOSÉ DE RIBAMAR, 2015, p. 27), o IDEB do Ensino Fundamental - Anos Iniciais ( $5^{\circ}$ ano) - atingiu em 2005, 3,5 e em 2013, 4,4. No que diz respeito ao Ensino Fundamental - Anos Finais ( $9^{\circ}$ ano), o município atingiu 3,1 em 2005, e em 2013, 4,0. Esse município é o terceiro município mais populoso do estado do Maranhão e integra a ilha de São Luís. Sua população é de 163.045 mil habitantes, segundo o Instituto Brasileiro de Geografia e Estatística (IBGE, 2010). As principais atividades econômicas do município são: pesca, comércio, turismo, principalmente religioso, serviços e indústrias.

Optamos pela abordagem da pesquisa qualitativa, pois conforme Bogdan e Biklen (1994) a pesquisa qualitativa é base da investigação em educação, por seu movimento dinâmico, que até pouco tempo,

[...] dominado pelas questões da mensuração, definições operacionais, variáveis, teste de hipóteses e estatísticas alargou-se para contemplar uma metodologia de investigação que enfatiza a descrição, a indução, a teoria fundamentada e o estudo das percepções pessoais. (BOGDAN; BIKLEN, 1994, p.11).

Segundo Ludke e André (1986, p.1), "para realizar uma pesquisa, é preciso promover o confronto entre os dados, as evidências, as informações coletadas sobre determinado assunto e o conhecimento teórico acumulado a respeito dele". Nesse sentido, apresentam algumas características sobre os estudos do tipo qualitativo como: a pesquisa de campo como base dos dados investigados, o que atribui ao contato direto do pesquisador um grande valor, tendo como preocupação básica o estudo e a análise do mundo empírico, o que exige do pesquisador observação, seleção, análise e interpretação dos dados coletados.

Os dados foram coletados por meio de observações, com inserções na escola e registro em diário de campo, entrevistas semiestruturadas, além de consultas a documentos.

Para efeito deste estudo, trazemos brevemente essa introdução. Na primeira seção os conceitos de educação integral e tempo integral. Em seguida, discutimos sobre a formação continuada de professores, condições de trabalho e currículo no contexto da escola de tempo integral. Finalmente, fundamentando-nos nas entrevistas com os professores, e a partir dessas, evidenciamos suas percepções sobre a experiência que vivenciam. A fundamentação teórica

\footnotetext{
${ }^{1}$ IDEB é o Índice de Desenvolvimento da Educação Básica, criado em 2007, pelo Instituto Nacional de Estudos e Pesquisas Educacionais Anísio Teixeira (Inep), formulado para medir a qualidade do aprendizado nacional e estabelecer metas para a melhoria do ensino. Disponível em: http://portal.mec.gov.br/conheca-o-ideb acesso em: 01 mar. 2019.
} 
contou coma contribuição de estudos de Cavaliere (2009), Moraes (2009), Tardif e Lessard (2014), dentre outros.

\section{Educação integral e tempo integral}

Consideramos oportuno evidenciar alguns conceitos mais gerais e não menos importantes, uma vez que tratamos de aspectos de relevância na escola de tempo integral, como os conceitos de Educação Integral e Tempo Integral. Segundo Coelho (2009), apesar de essas concepções teóricas dependerem da vertente política à qual aderem, a ideia de uma educação integral é comum às diversas propostas de organização social.

De acordo com Vetorazzi (2011, p. 13), o conceito de Educação Integral "surgiu no século XIX, fomentado pela ideia de emancipação humana, que propunha, por meio do socialismo em suas diversas correntes, o fim da exploração e do domínio capitalista imposto ao homem". A autora ressalta que

A sua origem esteve bem marcada no movimento operário que surgiu com a Revolução Francesa, a partir de quando os trabalhadores passaram a lutar para que o Estado fornecesse um sistema educacional que propiciasse melhores oportunidades e condições de educação para eles e para seus filhos. (VETORAZZI, 2011, p.13)

Moraes (2009), no ensaio "Educação integral: uma recuperação do conceito libertário" traz, numa perspectiva histórica, conceitos de Educação Integral, tal como aparecem no movimento operário do século XIX, especialmente na corrente anarquista, destacando nomes, como Robert Owen, Etienne Cabet, Charles Fourier, Mikail Bakunin, dentre outros, salientando como ponto central no pensamento destes a relação trabalho e educação.

É pertinente mencionar que esses pensadores tinham em comum a visão de que a educação seria transformadora, desde que aliasse o trabalho manual e o intelectual, a educação científica e a industrial, de modo que os aspectos físicos e intelectuais fossem postos de forma coerente e proporcional. Embora cada um tenha sua especificidade de pensamento, o conceito de educação integral revela-se aliado ao desenvolvimento do ser humano de forma completa, como sujeito e cidadão da história, com vistas a uma educação de sujeitos para uma sociedade igualitária.

Moraes (2009) traz ainda uma breve definição do termo integral, baseado no conceito do Dicionário Michaelis (1998), como inteiro, total, íntegro, não corrupto. Seguindo esse entendimento, podemos entender que a concepção de Educação Integral está ligada à ideia de 
uma formação que desenvolve os múltiplos aspectos de produzir conhecimento nos planos cognitivo, social, afetivo, cultural, físico, estético, entre outros; ou seja, sugere a ideia de uma formação "mais completa possível” para o ser humano (COELHO; HORA, 2011).

Já tempo integral ${ }^{2}$ se refere ao aumento da carga horária, isto é, à reestruturação do tempo escolar, e, intrínseca a essa proposta, está a reestruturação do currículo, dos espaços, e mais profissionais na escola. É importante salientarmos que as determinações legais de uma política de tempo integral não necessariamente se relacionam com o objetivo de formação integral do ser humano. Como bem lembra Menezes (2009), o estabelecimento do progressivo aumento do tempo escolar pode ser associado a diversos fatores, como por exemplo, aqueles relacionados à proteção social da criança e do adolescente, aos direitos de pais e mães trabalhadores.

\section{A formação continuada de professores da escola de tempo integral: alguns apontamentos}

De acordo com Ramalho, Nuñez e Gauthier (2003), desde o início dos anos 1990 assistese à emergência de novos discursos visando à formação e à profissionalização do ensino, em contraposição à formação docente baseada numa racionalidade fechada, exógena aos professores. No âmbito da formação continuada, trata-se de uma perspectiva de formação que se diferencia, por considerar o professor como sujeito da sua própria prática.

Os educadores são unânimes em reconhecer a importância da formação inicial e continuada. A formação inicial consistente, com fundamentos teóricos e práticos, acrescida da formação continuada para (re)construção de saberes e práticas pedagógicas, em um contexto de constantes mudanças, é basilar.

O tema torna-se ainda mais desafiador ao tratarmos da formação continuada de professores que atuam na escola de tempo integral, visto que, conforme Cavaliere (2009, p.51),

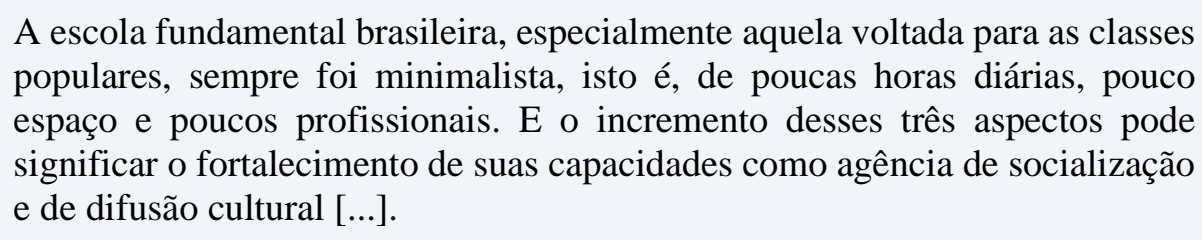

As discussões sobre a concepção que deve fundamentar a formação continuada de professores é motivo de profundas discussões no Brasil.

\footnotetext{
${ }^{2}$ De acordo com o Decreto $\mathrm{n}^{\mathrm{o}} 6.253 / 2007$, art.4 ${ }^{\text {; }}$, tempo integral refere-se a uma jornada escolar igual ou superior a sete horas diárias.
} 
Vários autores ${ }^{3}$ recusam o conceito de formação continuada significando treinamento, reciclagem, capacitação, cursos, seminários, palestras e outros desta natureza, existindo assim críticas contundentes a modelos tradicionais "que em geral priorizam o desenvolvimento institucional - de quem oferece - e não o desenvolvimento pessoal - que deve permear a formação continuada" (MENDES SOBRINHO, 2006, p.77). Logo, assumimos a concepção de formação continuada como processo, havendo preferência por formação continuada como prática reflexiva.

Para Libâneo (2000, p. 123): “a formação continuada consiste de ações de formação dentro da jornada de trabalho e fora dela. Ela se faz por meio do estudo, da reflexão, da discussão e da confrontação das experiências dos professores". Portanto, é um continuum, inacabado, que não se constrói por acumulação de conhecimentos, mas sim por meio de um trabalho sobre as práticas e de (re)construção constante de uma identidade.

No contexto da escola de tempo integral, a questão sobre a formação do professor ganha um novo olhar. Para atuação nas escolas de tempo integral, é necessário um novo professor, uma nova formação, além de uma nova organização do seu trabalho, do seu tempo, do planejamento. De acordo com Oliveira (2018), nas últimas décadas houve uma retórica envolvendo a formação docente, insistindo em sua capacidade de desenvolver a autonomia, a confiança e o domínio profissional, no que se refere aos professores da Educação Básica.

Neste sentido, esse novo olhar sobre o professor, sua formação e organização do seu trabalho, está na exigência do professor ser multiprofissional, multipedagógico, multicultural, sem, contudo, provê-lo de condições objetivas para tal (COELHO, 2002). É notório que os processos de transformação em curso na sociedade trazem o surgimento de novas demandas de organização social, no que se refere ao mundo do trabalho, em especial, são criados novos processos de atuação para o trabalhador, requerendo o desenvolvimento de novas habilidades cognitivas e comportamentais. (CABRAL NETO; MACÊDO, 2006). O professor não fica a parte, pois, tais mudanças ocorridas na sociedade geram mudanças para a formação do profissional.

Assim, na escola de tempo integral, "a ênfase estaria no fortalecimento da unidade escolar, com mudanças em seu interior pela atribuição de novas tarefas, mais equipamentos e

\footnotetext{
${ }^{3}$ Freitas (2002) enfatiza que no âmbito da formação continuada as políticas têm reforçado a concepção pragmatista e conteudista da formação de professores, bem como projetos de educação e formação que privilegiam o controle do desempenho com vistas à competência e competitividade em contraposição a uma outra concepção de educação e de formação que é a formação humana omnilateral, a autonomia e o aprimoramento pessoal. . Em especial Mendes Sobrinho (2002) discute os termos reciclagem, treinamento, capacitação, e enfatiza que estes carregam consigo distintas compreensões epistemológicas e pedagógicas acerca da atuação docente e do papel do professor.
} 
profissionais com formação diversificada, pretendendo propiciar a alunos e professores uma vivência institucional de outra ordem”. (CAVALIERE, 2009, p.53)

Em suma, a formação continuada é um investimento nas condições objetivas da prática de ensino e do trabalho pedagógico e, na sua subjetividade, para que continuem mantendo a convicção sobre o projeto ao qual se dedicam. Sua falta prejudica não só a formação desses profissionais, mas também o projeto que desenvolvem.

\section{Condições de trabalho na escola de tempo integral}

Os processos de transformação em curso na sociedade e o surgimento de novas demandas de organização social e no mundo do trabalho evidenciam que tais mudanças trazem novos processos de atuação para o trabalhador. Logo, os profissionais da educação não ficam à parte, pois são geradas mudanças para sua formação e atuação profissional.

No que se refere à escola de tempo integral, a ausência ou presença de condições estruturais e pedagógicas, número de profissionais para a sua materialização influenciam diretamente nas condições de trabalho docente e na qualidade social do ensino. Essas questões são relevantes para se entender o cenário da escola de tempo integral, pois, de modo geral, as reformas educacionais iniciadas nos anos de 1990 impactaram fortemente a educação e o trabalho docente, devido à intensificação do trabalho do professor, à precarização de condições estruturais e pedagógicas, além da desqualificação de seu trabalho.

Para Noronha (2001 apud OLIVEIRA, 2004), muitas vezes esses profissionais são obrigados a desempenhar funções de agente público, assistente social, enfermeiro, psicólogo, entre outras. Exigências que estão além de sua formação, o que contribui para um sentimento de desprofissionalização, de perda de identidade profissional, da constatação de que ensinar, às vezes, não é o mais importante. Essa nova regulação educativa apela ainda para o comunitarismo e voluntariado, de modo que mais responsabilidades sejam assumidas pela comunidade escolar, ao mesmo tempo em que retiram a autonomia do professor, entendida como condição de participar da concepção e organização de seu trabalho.

Para Oliveira "o trabalho docente não é definido mais apenas como atividade em sala de aula. Ele agora compreende a gestão da escola no que se refere à dedicação dos professores ao planejamento, à elaboração de projetos, à discussão coletiva do currículo e da avaliação" (OLIVEIRA, 2004, p. 1332). De modo geral, trabalho docente diz respeito às relações de trabalho do professor na sociedade capitalista, que comporta ainda inúmeras outras discussões 
e estudos que perpassam pelas mudanças na organização do seu trabalho e pelas condições materiais; às formas de inserção no mundo do trabalho; à necessidade de planos de carreira; à desvalorização social da profissão, entre outras.

Nessa direção, Tardif e Lessard (2014) indicam algumas questões que marcam o trabalho docente, como, por exemplo, a carga de trabalho dos professores, que pode ser analisada tanto da perspectiva "administrativa", isto é, considerando normas oficiais (decretos, leis, convenções coletivas, etc.) que procedem do governo e de negociações de suas entidades representativas quanto da perspectiva das exigências reais do trabalho cotidiano. Os autores chamam atenção também para a noção de "carga de trabalho" que é complexa, visto que remete a diversos fenômenos que se intercruzam; têm influência recíproca e difícil de separar completamente, e eles destacam os principais fatores que devem ser considerados na determinação da carga de trabalho dos professores, quais sejam:

a) Fatores materiais e ambientais, como a natureza dos lugares de trabalho e os recursos materiais disponíveis. Por exemplo, a insuficiência de material adequado, a falta de equipamento informático, a pobreza das bibliotecas, a dependência dos horários de transporte (em regiões distantes), a insuficiência de recursos financeiros. [...]

b) Fatores sociais, como a localização da escola, a situação socioeconômica dos alunos e de sua família, a violência [...], a venda de drogas entre crianças, etc.

c) Fatores ligados ao "objeto de trabalho", tais como o tamanho das turmas, a diversidade de clientelas, a presença de alunos com necessidades especiais e com dificuldades de adaptação e de aprendizagem, a idade dos alunos, o sexo, o nível de maturidade, etc.

d) Fenômenos resultantes da organização do trabalho: tempo de trabalho, o número de matérias a dar, o vínculo empregatício (regular, precário, por contrato, etc.), a diversidade das outras tarefas além do ensino (a recuperação, as atividades paradidáticas, etc.) as atividades à noite, nos fins de semana, nas férias, etc.

f) Exigências formais ou burocráticas a cumprir: observância de horários, avaliação dos alunos, atendimento aos pais, reuniões obrigatórias, tarefas administrativas, etc. (TARDIF; LESSARD, 2014, p. 113-114).

Segundo os autores, esses fatores não se somam, simplesmente; eles também atuam em sinergia, para criar uma carga de trabalho complexa, variada e portadora de tensões diversas.

Como podemos perceber a presença de condições estruturais e pedagógicas, de número de profissionais, de especialidades e condições de trabalho docente, são fatores primordiais para a consolidação da proposta. Portanto, a variedade de profissionais e áreas de conhecimento na escola de tempo integral é de suma importância, pois ela se alia à ideia de profissionalização dos educadores, que atuam conforme sua formação, qualificação acadêmica, sem sobrecarga de funções. Para Coelho (2002), a melhoria das condições de trabalho depende de cada espaço 
escolar específico e também do projeto político-pedagógico implementado na instituição; depende mais ainda da resistência e organização dos docentes.

\section{Escola de tempo integral e currículo}

Dentre as muitas articulações possíveis com a escola de tempo integral, o currículo é imprescindível, ainda mais quando se problematiza a formação e atuação de professores no contexto da escola de tempo integral, que se apresenta como alternativa de uma educação transformadora e pela possibilidade de efetivação de um Currículo Integrado ${ }^{4}$.

O campo de estudo do currículo é sem dúvida desafiador, pois não há um tema central, mas temas centrais que se inter-relacionam e influenciam direta e/ou indiretamente no processo de ensino e aprendizagem. Nesse contexto desafiador, reafirma-se a dificuldade de definição precisa dos seus objetos de estudos, as divergências teóricas e políticas, as avaliações que instituem a lógica do desempenho para a escola, as questões de conhecimento e poder, os impasses na formação docente, entre outras (FAVACHO, 2013).

É evidente que os desafios postos no currículo não estão alheios às questões sociais e políticas, que, algumas vezes, são postas numa perspectiva de controle social; em outras, numa tentativa de promover a inclusão de alguns grupos e temas, na perspectiva de superação das desigualdades. Portanto, os dilemas são vários, e a questão "Que conhecimento deve ser ensinado?” está diretamente ligada a relações de poder, à valorização de uma cultura, de conhecimentos que valorizam as tradições de uma classe ou grupo. Por isso, o conhecimento escolar não é neutro, mas sim, fruto de conflitos e negociações, de modo que categorias, como ciência, cultura e trabalho, merecem ser analisadas numa perspectiva integradora e de formação humana.

Não pretendemos neste estudo abordar conceitos discutidos nas teorias tradicionais, críticas e pós-críticas que permeiam o currículo, mas, conforme Silva (1999, p.16) reafirmar a relevância de conhecê-las, visto que "Os conceitos de uma teoria dirigem nossa atenção para certas coisas que sem eles não 'veríamos'.”. William Pinar recorre à etimologia da palavra curriculum, destacando que ela significa originalmente "pista de corrida", deriva do verbo currere, em latim, correr. É, antes de tudo um verbo, uma atividade. "É como atividade que não se limita à nossa vida escolar, educacional, mas à nossa vida inteira" (SILVA, 1999, p.43).

${ }^{4}$ De acordo com Lopes (2006), Currículo Integrado pode ser definido como uma forma de organização do conhecimento escolar capaz de garantir a melhoria do processo de ensino-aprendizagem e/ou estabelecimento de relações menos assimétricas entre os saberes e os sujeitos no currículo. 
Sendo assim, o conceito de currículo que é polissêmico confirma que este deve ser entendido numa concepção ampla, pois é multifacetado e modifica-se historicamente, a fim de atender tempos e espaços específicos. Podemos então, entender currículo num primeiro momento, como uma seleção de conteúdos e organização de experiências de aprendizagem, que envolve planejamento e orientação, visto ser, este é objetivamente a materialização das políticas na escola, na formação de professores, etc.; podemos entendê-lo ainda como um conjunto sistematizado de elementos que compõem o processo educativo e a formação humana (MOTA; BARBOSA, 2004).

Em outras palavras, ao enfatizarmos a formação humana, colocamos em evidência a formação de uma identidade social, como bem afirma Silva (1999) ao destacar que entre as múltiplas possibilidades, uma identidade ou subjetividade como sendo a ideal é uma operação de poder. É nesse aspecto que a reflexão do professor deve ultrapassar os "limites" da sala de aula, da escola, e interligar-se a contextos sociais, econômicos, culturais, compreendendo que os processos de formação de sujeitos se fazem, sobretudo, pela diversidade e não pela uniformização.

Para Fávero e Tonieto (2010, p.75, grifos dos autores), “Toda prática docente é carregada de intencionalidade, seja ela refletida ou não. Toda prática docente busca intervir na e contribuir para a formação de outros”. Desse modo, quando os sujeitos da escola se reúnem para discutir objetivos, ações, metas, estratégias, procedimentos cotidianos e proposta pedagógica, estão definindo seu currículo, além do formal e sua posição diante da sociedade, visto que todas as relações vivenciadas na escola fazem parte do currículo real: as relações entre professores, entre a gestão e a comunidade escolar. E, de acordo com a intencionalidade que se tem, são pensadas ações, intervenções e contribuições (FÁVERO; TONIETO, 2010).

Assim, compreendemos que formação continuada é imprescindível, para que o professor dê conta de apreender o currículo da escola de tempo integral; é um direcionamento na tarefa de ensinar e aprender, bem como de entender e superar os desafios do cotidiano nas práticas pedagógicas. Reafirmamos, conforme Santos e Favacho (2012), que as políticas e propostas curriculares são mediatizadas não apenas pelos órgãos gestores locais e pelas instituições escolares, mas, principalmente, pelo trabalho docente. Daí a compreensão pelo professorado de que o currículo é de suma importância, uma vez que, a partir do conhecimento que temos dele, há uma modificação na forma de organizar nosso trabalho e enfrentarmos as dificuldades que encontramos em seu desenvolvimento. 
É evidente que, ao discutirmos sobre a escola de tempo integral e de qual tipo de profissional ela necessita e como formá-lo, a questão tem relação direta com uma formação consistente, que permita ao professor ser protagonista e não mero técnico na aplicação do currículo, na perspectiva de profissionalização docente.

Segundo Coelho (2002, p.141), "não há possibilidade de compromisso efetivo quando o profissional não dispõe de períodos para refletir sobre seu próprio cotidiano de trabalho, principalmente quando essa tarefa envolve a formação de seres humanos". Assim, a questão do currículo na escola de tempo integral é duplamente importante, tanto para o aluno e seu aprendizado quanto para o professor na sua preparação para mediar os conhecimentos.

\section{A percepção dos sujeitos sobre a escola de tempo integral}

Neste recorte da pesquisa, discutimos e analisamos sobre formação continuada, as condições fundamentais para um bom funcionamento da escola de tempo integral e os aspectos positivos e negativos das condições de trabalho de professores que atuam na escola de tempo integral. A pesquisa foi feita no período de dezembro de 2015 a abril de 2016, referindo-se à experiência vivenciada por eles, no período de 2008 a 2012 para atuarem na escola de tempo integral, anos iniciais de sua implantação.

É importante destacarmos, conforme Bogdan e Biklen (1994), que a pesquisa qualitativa é base da investigação em educação, por seu movimento dinâmico, que até pouco tempo,

[...] dominado pelas questões da mensuração, definições operacionais, variáveis, teste de hipóteses e estatísticas alargou-se para contemplar uma metodologia de investigação que enfatiza a descrição, a indução, a teoria fundamentada e o estudo das percepções pessoais (BOGDAN; BIKLEN, 1994, p.11).

Para Minayo (2007, p. 44), “a pesquisa qualitativa considera a visão, o juízo, o ponto de vista dos interlocutores, busca o aprofundamento e a abrangência da compreensão seja de um grupo social, de uma organização, de uma instituição ou de uma política”.

Assim, na intenção de dialogar com as referências teóricas, procuramos conversar, observar, registrar em um caderno do tipo "diário de campo" as memórias dos professores, os eventos da escola (no período de dezembro de 2015 a abril de 2016) e coletar dados.

Apontamos quatro momentos principais da pesquisa: $1^{\circ}$ Observação do cotidiano escolar: consistiram em observações diretas no âmbito do cotidiano, como apresentação de projetos didáticos e culturais, palestras, reuniões, que envolvem diretamente professores e 
alunos (no processo ensino-aprendizagem). $2^{\circ}$ Realização de entrevistas semiestruturadas com os Professores, com a Coordenadora Pedagógica e Secretária Adjunta de Gestão Pedagógica. $3^{\circ}$ Análise documental dos diferentes registros da proposta da escola de tempo integral tanto em âmbito nacional como local.

Os sujeitos da pesquisa foram: (01) coordenadora pedagógica; (09) professores (anos iniciais e finais do ensino fundamental), (01) Secretária Adjunta de Gestão Pedagógica, totalizando 11 sujeitos. Dividimos a entrevista por blocos de questões direcionadoras, aqui explanamos o Bloco 01: Concepção de tempo integral, do qual fazemos algumas análises. Para identificação dos sujeitos da pesquisa, optamos pela inscrição Professor (P): P01, P02, P03 até P09; para Coordenadora Pedagógica (CP) e para Secretária Adjunta de Gestão Pedagógica (SAGP).

Propomos o bloco de discussão sobre Concepção de tempo integral, em que perguntamos: Para você, quais condições são fundamentais para um bom funcionamento da escola de tempo integral? A formação continuada dos professores integra o PPP (Projeto Político Pedagógico) da escola? Comente aspectos positivos e negativos de suas condições de trabalho na $\operatorname{ETI}^{5}$ (Escola de Tempo Integral)?

Vejamos os relatos mais expressivos:

P02: "A estrutura física e um bom currículo. Sim, no documento do PPP tem formação continuada, na prática não. Os pontos positivos são: tempo pra trabalhar a disciplina, salas especiais como informática, ciências, biblioteca; temos recursos didáticos. Como negativo eu acho que a estrutura física deveria ser melhorada, tem muito conteúdo, e temos muitos alunos por classe".

P04: "Ter atividades diversificadas e em espaços diferentes é essencial. A escola tem PPP, mas eu não tenho conhecimento se a formação continuada faz parte. Os pontos positivos são espaço físico, boa limpeza. Uma coisa que eu acho negativo é que nossa opinião precisa ser mais considerada".

P06: [...] aulas pela manhã e, à tarde, atividades diversificadas (dança, música, teatro, esportes, usos do laboratório de informática) e ter uma equipe multidisciplinar, porque trabalhos com projetos que são bons mesmo [...], mas sempre fica com a gente. Aqui tem PPP [...] tem esse aspecto da formação continuada, mas a realidade é que cada um é responsável pela sua própria formação; se fôssemos depender de SEMED não teríamos nada. Os positivos são o bom salário, a coordenação pedagógica atuante ao lado dos professores, com os pais e alunos; como negativos, atividades extraclasses deixam a desejar, tornam nosso trabalho maçante e sem dinamismo.

${ }^{5}$ Usaremos a sigla ETI para nos referirmos à Escola de Tempo Integral. 
P09: "As condições fundamentais são boa estrutura física para manter os alunos, uma equipe docente competente, uma equipe multidisciplinar, a formação continuada para professores e cursos para os outros profissionais da escola. Aqui tem PPP, mas formação continuada de fato não. Eu considero positivo, em parte a estrutura física, porque já deveria ter algumas melhorias; os materiais pedagógicos; negativo a falta de tempo para estudar, a escola é conteudista, também precisariam de mais banheiros para que os alunos pudessem ter melhor higiene, a maioria das atividades tem que ser na sala de aula".

Dentre os aspectos relatados como fundamentais para o funcionamento da ETI, os professores destacam: estrutura física adequada, currículo, profissionais competentes, gestão administrativa e pedagógica atuantes, atividades diversificadas e uma equipe multidisciplinar, participação da família, atividades em espaços socioeducativos diferentes, recursos didáticos em todas as áreas.

Ao destacarem como condição fundamental a existência de profissionais competentes, a formação continuada se mostra como temática e necessidade, visto que necessitam refletir sobre suas práticas e saberes, bem como opinar, sugerir, discutir sobre contexto que vivenciam. Fica evidente também que ao destacarem como condição fundamental as atividades diversificadas, a equipe multidisciplinar, os espaços socioeducativos diferentes, estão relacionando com o currículo, pois expõem a necessidade de propiciar experiências diversas de aprendizagem, distanciando-se do repetitivo, mas da necessidade de uma nova forma de construção do conhecimento.

Neste sentido, Guará (2006), ao discutir a ampliação do foco do processo para a rede de espaços de aprendizagem, que vale tanto para os projetos de trabalho no âmbito da escola quanto para aqueles desenvolvidos em outros contextos educativos, defende que, no cerne das preocupações com a aprendizagem, esteja a ideia de permitir que as vivências e a ação pedagógica conduzam a uma integração dos conhecimentos e saberes tanto da esfera acadêmica quanto da vida social. Daí a necessidade de interlocução com outras instituições socializadoras e educadoras, como a família, a igreja, as bibliotecas, os museus, os clubes esportivos, as organizações sociais e outros tantos espaços de aprendizagem que a cidade oferece.

Por isso, é importante que essas políticas tenham um planejamento contínuo, que possibilite parcerias entre diversos campos do conhecimento (arte, cultura, tecnologia, esporte) e que se realizem não apenas no espaço da escola, mas também nos diversos espaços socioculturais, com ações socioeducativas bem conectados com a vida, fazendo uma composição coerente no que se refere a aprendizagens e saberes, territorialização e contextualização, intersetorialidade e interdisciplinaridade e formação de professores. 
Essas condições e processos relatados como fundamentais, são, ao mesmo tempo, desafios que os professores enfrentam, confirmando que a implementação de políticas educacionais voltadas para a escola de tempo integral precisa ser mais bem planejada nesses aspectos.

Lembramos que a ausência ou presença de condições estruturais, pedagógica e de recursos humanos influenciam diretamente nas condições de trabalho docente e na qualidade social do ensino. Existe ainda a necessidade de uma equipe multidisciplinar como apoio pedagógico ao trabalho dos professores e aos alunos, interferindo nas reais condições de trabalho dos professores da escola de tempo integral, onde "todos fazem tudo".

Ainda sobre o bloco Concepção de tempo integral, buscamos a percepção da coordenadora pedagógica (CP), os questionamentos abordaram: O que a motivou para ingressar nessa escola de tempo integral? Qual a concepção de escola de tempo integral proposta na formação continuada desenvolvida com os professores? A metodologia utilizada na formação continuada tem ajudado em sua compreensão sobre a concepção de escola de tempo integral? Explique. Para você, quais condições são fundamentais para um bom funcionamento da escola de tempo integral? A formação continuada dos professores integra o PPP da escola?

CP: Eu já era professora da Rede, e a motivação foi o desafio de trabalhar com algo novo aqui no município. Já tinha ouvido falar da proposta de Anísio Teixeira e depois dessa escola aqui mesmo.

CP: A SEMED enfatiza para nós que a ETI é além do tempo; ela precisa oferecer atividades culturais, científicas [...] precisa articular escola e mundo, precisa desenvolver um ensino amplo, e nossa equipe se esforça para fazer isso. Por exemplo, com a metodologia de projetos, tentamos articular o conhecimento. Por outro lado, faltam condições objetivas, as parcerias [...] as coisas que acontecem são por causa do grupo, e não há uma formação específica para nós de tempo integral.

CP: Quanto às condições fundamentais para o bom funcionamento da ETI, penso que são: pessoal docente capacitado, equipe multidisciplinar, recursos didáticos e pedagógicos (e sua constante revitalização), estrutura física, equipamentos novos. A formação continuada integra o PPP como algo que deve ser incentivado, mas não de modo específico.

Fica manifesta nessas declarações a motivação da CP de trabalhar em uma experiência nova no município. Porém há divergências nos depoimentos desta e dos professores, pois para estes não houve/não há direcionamento quanto à concepção de tempo e metodologia desse projeto de educação no município, cada um é responsável pela sua formação continuada. Ainda que a SEMED (Secretaria Municipal de Educação) tenha o entendimento de "que a ETI é além 
do tempo, ela precisa oferecer atividades culturais, científicas [...] precisa articular escola e mundo, precisa desenvolver um ensino amplo", como relatado por ela $\mathbf{C P}$, e, embora haja esforço dos professores para isto, é necessário real fomento com formação continuada, condições objetivas físicas e pedagógicas, parcerias, enfim, investimento contínuo, para além de gestões municipais, mas como política de educação do município.

A CP deixa explícita a necessidade de uma formação continuada que contemple as especificidades da ETI, bem como a importância desta para o bom funcionamento da proposta, a necessidade de equipe multidisciplinar, dentre outros, e também que existe no Projeto Político-Pedagógico referência à formação continuada como algo importante a ser incentivado, mas não como uma ação concreta a ser desenvolvida.

Nesse sentido, destaca Alarcão (2003, p. 102):

[...] para que os professores na escola sejam autênticos profissionais do desenvolvimento humano, é preciso que a escola seja primeiro de tudo, um centro de formação para todos os que nela convivem, incluindo os professores, e que esteja organizada para nela se viver em conjunto um projeto: seu projeto de formação.

Por isso, a formação continuada dos professores da ETI deve realmente contemplar as necessidades e expectativas destes profissionais, para que possam não em parte, nem "mais ou menos" compreender a proposta (concepção e metodologia) da escola de tempo integral indicada pelo município, mas contribuir efetivamente para a melhoria, tendo como base fundamentos filosóficos, sociológicos, pedagógicos, propostas de experiências práticas que embasem suas ações quanto ao conhecimento e as práticas em uma proposta fundamentada e concreta. Conforme os dados levantados na escola e na própria SEMED, não há documentação sobre a proposta de formação continuada de professores. Estes apenas seguem as Diretrizes Nacionais para Formação de Professores. E, como já dito, não foi disponibilizado o PPP da escola e nem a Matriz Curricular, para que pudéssemos fazer outras análises.

Direcionamos a entrevista sobre Concepção de tempo integral também à Secretária Adjunta de Gestão Pedagógica (SAGP) com as seguintes questões: Qual a concepção de escola de tempo integral proposta na formação continuada desenvolvida com os aos professores? A metodologia utilizada na formação continuada tem ajudado os professores na compreensão sobre a concepção de escola de tempo integral? Explique. Para você, quais condições são fundamentais para um bom funcionamento da escola de tempo integral?

SAGP: É trabalhada a ideia de realidade dos alunos, para desenvolver suas capacidades com diversas atividades (palestras sobre meio ambiente, 
trânsito, etc.), e trabalhar com as habilidades do professor para que possa desenvolver no aluno essas capacidades.

SAGP: A metodologia ajuda, pois, os professores discutem textos, planejam e desenvolvem um bom trabalho, tanto é que temos bons índices no IDEB.

SAGP: As condições necessárias para o bom funcionamento da ETI são espaço físico adequado, recursos humanos capacitados e recursos financeiros.

Essas declarações dadas pela SAGP divergem dos depoimentos dos professores das Séries Iniciais que declararam que a formação continuada consta como aspecto importante no PPP, mas não se evidencia na prática como necessidade específica da ETI para enfrentamento de seus desafios, embora também afirmem que têm algumas discussões de textos, reuniões, Semana Pedagógica e capacitações para uso de livros didáticos; já os professores das Séries Finais afirmaram não ter nenhum tipo de formação continuada, e que buscam continuidade de estudos por iniciativa própria.

Advertimos que essa relação direta citada pela SAGP, quanto à metodologia desenvolvida ajudar no entendimento dos professores sobre a ETI, visto que discutem textos, planejam e desenvolvem um bom trabalho e têm bons índices no IDEB, não é uma relação assim tão linear, pois os professores buscam individualmente promover sua formação e há ressalvas a serem consideradas quanto ao que é oferecido pelo município como formação continuada.

Assim, a participação coletiva na escola para a construção de objetivos comuns, de concepções bem fundamentadas de tempo, espaço, metodologias, estratégias e avaliação é uma das possibilidades de enfrentamento a desafios e novas perspectivas que consolidem o projeto da ETI para além das avaliações nacionais, de gestões municipais, mas com intencionalidade de formação educativa transformadora e bem-estar dos sujeitos que a vivenciam.

A escola de tempo integral é terreno fértil para as discussões e análises sobre a educação. No que se refere a essa realidade específica, está em andamento uma experiência rica que transcende o campo técnico-instrumental e oferece muitas dimensões de estudo.

\section{Considerações finais}

Os estudos e discussões sobre a escola de tempo integral e seus intercruzamentos têm contribuído para refletirmos sobre as políticas, a formação continuada de professores, as condições de trabalho docente, o currículo, cada um a seu modo tem sua complexidade e exige 
um aprofundamento, observamos que expressam em comum a relevância do processo formativo, da crítica, da luta dos professores e das possibilidades da ação humana.

Dada a multiplicidade de olhares discutidos pelos autores, coadunamos com a ideia de formação como um continuum, um processo, que não se constrói por acumulação de conhecimentos, mas sim, por meio de um trabalho sobre as práticas e de (re)construção constante de uma identidade, constante pensar e fazer.

Discutir as condições de trabalho de professores é essencial, pois nela estão imbricadas também as questões normativas e burocráticas, os dilemas internos e de classe dos docentes, enfim, questões como jornada de trabalho, número de alunos, instrumentos de trabalho, salário, dentre outros temas que se caracterizam pela constante mobilização da classe docente frente às pressões do mundo do trabalho, tensões e necessidades.

O currículo, em sua rotina escolar, expressa a formação de identidade, de relações de poder, e também a possibilidade de manter ou transformar o status quo, sua compreensão é basilar para se fazer as análises no que está explícito e implícito no conhecimento escolar.

No âmbito da escola de tempo integral essas questões se potencializam, pois a formação continuada de professores, as condições de trabalho, o currículo, dentre outros, compõem um cenário formativo, defendido por alguns autores, nesse contexto, como uma proposta de vivência institucional de outra ordem para professores e alunos.

Assim, essa temática confirma sua recorrência não só pela questão instrumental, mas também política e social, pela relevância de retroalimentar essa agenda de discussão e pesquisa que nos permite conhecer, questionar, desmistificar, mesmo diante das dificuldades e divergências, vislumbrando melhorias de práticas e experiências de formação docente de qualidade.

\section{REFERÊNCIAS}

ALARCÃO, Isabel. Formação continuada como instrumento de profissionalização docente. In: VEIGA, Ilma Passos Alencastro (Org.) Caminhos da profissionalização do magistério. 3.ed. Campinas, SP: Papirus, 2003.

BRASIL, Ministério da Educação. Educação integral: texto referência para o debate nacional. Brasília: MEC: SECAD, 2009.

BRASIL. Decreto No 6.253, de 13 de novembro de 2007. Dispõe sobre o Fundo de Manutenção e Desenvolvimento da Educação Básica e de Valorização dos Profissionais da 
Educação - FUNDEB, regulamenta a Lei no 11.494, de 20 de junho de 2007, e dá outras providências. Diário Oficial da União: Brasília, DF, 14 nov. 2007.

BOGDAN, Robert; BIKLEN, Sari K. Investigação qualitativa em educação: uma introdução a teorias e aos métodos. Tradução Maria Alvarez, Sara Bahia dos Santos e Telmo Mourinho Baptista. Porto: Porto Editora, 1994.

CABRAL NETO, Antônio; MACÊDO, Valcinete Pepino. Os desafios da formação continuada de professores: uma reflexão sobre o programa gestar. In: CABRAL NETO, Antônio; MACÊDO, Valcinete Pepino. Política pública de educação no Brasil: compartilhando saberes e reflexões. Porto Alegre: Sulina, 2006.

CAVALIERE, Ana Maria. Escolas de tempo integral: uma ideia forte, uma experiência frágil. In: COELHO, Lígia M. C. C.; CAVALIERE, Ana Maria V. (Orgs.). Educação brasileira e (em) tempo integral. Petrópolis, RJ: Vozes, 2002, p.93-111.

CAVALIERE, Ana Maria. Escolas de tempo versus alunos em tempo integral. Em Aberto, Brasília, v.22, n. 80, p. 51-64, abr. 2009.

COELHO, Lígia Martha C. da Costa. Formação continuada do professor e tempo integral: uma parceria estratégica na construção da educação integral. In: COELHO, Lígia Martha C. da Costa; CAVALIERE, Ana Maria V. (Orgs.). Educação brasileira e (em) tempo integral. Petrópolis, RJ: Vozes, 2002, p. 133-146.

COELHO, Lígia Martha C. da Costa. História (s) da educação integral. Em Aberto, Brasília, v. 22 , n. 80 , p. 83-96, abr. 2009.

COELHO, Lígia Martha C. da Costa. HORA, Dayse Martins. Políticas públicas e gestão para a educação integral: formação de professores e condições de trabalho. In: SIMPÓSIO

BRASILEIRO DE POLITICA E ADMINISTRAÇÃO DA EDUCAÇÃO. 25.; CONGRESSO IBERO-AMERICANO DE POLÍTICA E ADMINISTRAÇÕ DA EDUCAÇÃO. 2.; 2011.

São Paulo. Anais [...] São Paulo: ANPAE, 2011 Disponível em:

http://www.anpae.org.br/simposio2011/cdrom2011/PDFs/trabalhosCompletos/comunicacoes Relatos/0285.pdf. Acesso em: 03 jan. 2013

FAVACHO, André Márcio Picanço. et al. Currículo, conhecimento e avaliação: divergências e tensões. 1.ed. Curitiba, PR: CRV, 2013.

FÁVERO, Altair Alberto. TONIETO, Carina. Educar o educador: reflexões sobre a formação docente. Campinas, SP: Mercado de Letras, 2010.

FREITAS, Helena Costa Lopes de. Formação de professores no Brasil:10 anos de embate entre projetos de formação. Educ. Soc., Campinas, v. 23, n. 80, set. 2002, p. 136-167.

GUARÁ, Isa Maria F. Rosa. É imprescindível educar integralmente. Cadernos Cenpec, São Paulo, v. 1, n. 2, 2006. Disponível em:

http://cadernos.cenpec.org.br/cadernos/index.php/cadernos/article/view/168. Acesso em: 13 out. 2015. 
INSTITUTO BRASILEIRO DE GEOGRAFIA E ESTATÍSTICA. São José de Ribamar: População. 2010. Disponível em: https://cidades.ibge.gov.br/brasil/ma/sao-jose-deribamar/panorama. Acesso em: 10 set. 2013.

LIBÂNEO, J. C. Organização e gestão da escola: teoria e prática. Goiânia: Alternativa, 2000.

LOPES, Alice Casimiro. Integração e disciplinas nas políticas de currículo. In: LOPES, Alice Casimiro; MACEDO, Elizabeth; ALVES, Maria Palmira Carlos. (Orgs.) Cultura e política de currículo. Araraquara, SP: Junqueira \& Marin, 2006.

LUDKE, Menga; ANDRÉ, Marli. E. D. A Pesquisa em educação: abordagens qualitativas. São Paulo: Pedagógica e Universitária, 1986.

MENDES SOBRINHO, José Augusto de Carvalho. A formação continuada de professores: modelos clássicos e contemporâneos. Linguagens, Educação e Sociedade. Teresina, ano 11, n. 15 , p. $75-93$, jul./dez. 2006.

MENEZES, Janaína S.S. Educação Integral e tempo integral na educação básica: da LDB ao PDE. In: COELHO, Lígia Martha C. da Costa. (Org.) Educação Integral em tempo integral: estudos e experiências em processo. Petrópolis, RJ: DP et Alii; Rio de Janeiro: FAPERJ, 2009.

MINAYO, M. C. de S. O desafio do conhecimento. 10. ed. São Paulo: HUCITEC, 2007.

MORAES, José Damiro de. Educação integral: uma recuperação do conceito libertário. In: COELHO, Lígia Martha C. da Costa. (Org.) Educação Integral em tempo integral: estudos e experiências em processo. Petrópolis, RJ: DP et Alii; Rio de Janeiro: FAPERJ, 2009.

MOTA, Carlos Ramos; BARBOSA, Najla Veloso Sampaio. O currículo para além das grades: construindo uma escola em sintonia com seu tempo. MEC/TV Escola. Brasília, jun. 2004.

OLIVEIRA, Dalila Andrade. A reestruturação do trabalho docente: precarização e flexibilização. Educação \& Sociedade, Campinas, v. 25, n. 89, p. 1127-1144, set./dez. 2004.

OLIVEIRA, Dalila Andrade; DOS SANTOS, Kildo Adevair. Políticas de Formação Docente e a Educação em Tempo Integral. Práxis Educacional, Vitória da Conquista, v. 14, n. 28, p. p.16-40, abr./jun. 2018. ISSN 2178-2679. DOI: https://doi.org/10.22481/praxis.v14i28.3412. Disponível em: http://periodicos2.uesb.br/index.php/praxis/article/view/3412. Acesso em: 23 mar. 2020.

RAMALHO, Betânia Leite; NUÑEZ, Isauro Beltran; GAUTHIER, Clermont. Formar o professor, profissionalizar o ensino: perspectivas e desafios. Porto Alegre: Sulina, 2003. 208p.

SANTOS, Lucíola L. de Castro Paixão; FAVACHO, André Márcio Picanço (Orgs.). Políticas e práticas curriculares: desafios contemporâneos. Curitiba, PR: CRV, 2012. 
SÃO JOSÉ DE RIBAMAR. Prefeitura Municipal de São José de Ribamar. Plano Municipal de Educação (2015/2024). São José de Ribamar: SEMED, 2015.

SILVA, Tomaz Tadeu da. Documentos de Identidade: uma introdução às teorias do currículo. Belo Horizonte: Autêntica, 1999.

TARDIF, Maurice; LESSARD, Claude. O trabalho docente: elementos para uma teoria da docência como profissão de interações humanas. 9. ed. Petropólis, RJ: Vozes, 2014.

VETORAZZI, Nilcéia Gomes. Escola de tempo integral: da convenção a participação.

Dissertação (Mestrado em Educação) - Universidade Cidade de São Paulo (UNICID). São Paulo, 2011. Disponível em:

http://arquivos.cruzeirodosuleducacional.edu.br/principal/old/mestrado_educacao/dissertacoes /2011/dissertacao_nilceia_gomes_vetorazzi.pdf. Acesso em: 03 jan. 2013.

\section{SOBRE AS AUTORAS:}

\section{Erika Christianne Sousa Pereira de Almeida}

Mestre em Educação pela Universidade Federal do Maranhão (PPGE/UFMA). Professora da Rede Municipal de Educação de São Luís. Integra o Grupo de Pesquisa Escola, Currículo e Formação Docente. E-mail: erikachristianne@gmail.com.

(iD http://orcid.org/0000-0001-9317-308X

\section{Lélia Cristina Silveira de Moraes}

Doutora em Educação pela Universidade Federal do Ceará UFC. Professora do Programa de Pós- Graduação em Educação PPGE/UFMA e do Curso de Graduação em Pedagogia da Universidade Federal do Maranhão. Integrante do Grupo de Pesquisa Escola, Currículo e Formação Docente. E-mail: lelia.silveira@ufma.br

(iD) http://orcid.org/0000-0002-7330-553X 